\title{
SCHOOLING AND SWIMMING BEHAVIORS OF HYLA SEMILINEATA TADPOLES (ANURA, HYLIDAE)
}

\author{
Anne d'Heursel ${ }^{1}$ \\ Célio F. B. Haddad ${ }^{1}$
}

\begin{abstract}
The schooling behavior of Hyla semilineata Spix, 1824 tadpoles is described. Experiments were carried out both in the natural environment and under controlled conditions to quantify the constant movement of these tadpoles. Bullfrog tadpoles (Rana catesbeiana Shaw, 1802), similar in size to the H. semilineata larvae, were used as controls in the experiments. Hyla semilineata tadpoles remained stationary for one sixth of the time that the bullfrog tadpoles did and the number of individuals of $H$. semilineata moving at any given moment was about seven times greater. The schooling behavior and constant swimming behavior of these tadpoles may enhance the effect of their warning coloration.
\end{abstract}

KEYWORDS. Hyla, Rana, Ranidae, larvae, Brazil.

\section{INTRODUCTION}

The tree frog Hyla semilineata Spix, 1824 inhabits the Atlantic rainforest on the coast of Brazil (HEURSEL \& DE SÁ, 1999). The tadpoles of this species are glossy black and form large, spherical schools. Experiments have shown that these tadpoles are distasteful to certain vertebrates and that their black color may have an aposematic function (Heursel \& Haddad, 1999).

WASSERSUG (1973) distinguished tadpole aggregates as being either simple or biosocial and the schools of $H$. semilineata tadpoles would fall into the latter category. The social aspects of tadpole aggregates have been studied in natural conditions and in the laboratory for a variety of species (WASSERSUG, 1973; WALDMAN, 1982; CALDWELL, 1989; ETEROVICK \& SAZIMA, 1999). WASSERSUG (1973) described two modes of biosocial aggregates, namely the Xenopus and Bufo modes. CALDwell (1989) reviewed Wassersug's terminology and classified the biosocial aggregates into three modes called Type I (Bufo Laurenti, 1768 and possibly some species of Leptodactylus Fitzinger, 1826), Type II (Xenopus Wagler, 1827, some species of Phyllomedusa Wagler, 1830, and some microhylids) and Type III (Hyla geographica Spix, 1824 and some species of ranids and rhacophorids). The function of schooling behavior in tadpoles has been discussed by several authors (Wassersug, 1973; Waldman, 1982; Guilford, 1988) and the most

1. Departamento de Zoologia, Universidade Estadual Paulista, Caixa Postal 199, 13506-900 Rio Claro, São Paulo, Brasil. 
probable advantages conferred by this behavior would be facility in acquiring food and decrease in predation risk. The current study was undertaken to verify the structure and possible function of the schools of $H$. semilineata tadpoles.

\section{MATERIAL AND METHODS}

Hyla semilineata tadpoles were collected in the Poço das Antas, Mongaguá and Massaguaçu Beach, Caraguatatuba, both in the State of São Paulo during the summer of 1993, 1994 and 1995. Bullfrog (Rana catesbeiana Shaw, 1802) tadpoles, reared in frog farms, were used as controls in the experiments. In the laboratory, the tadpoles were maintained in aerated dechlorinated water and fed on lettuce leaves and ornamental fish food. Random samples of tadpoles of the two species were measured for total length $(\mathrm{cm})$, and their developmental stages were identified according to GOSNER (1960) in order to match the sizes for each experiment. Stages 35-37 of $H$. semilineata tadpoles (mean total length $\pm \mathrm{SD}=5.14 \mathrm{~cm} \pm 0.51, N=56$ ) and stages 30-33 of $R$. catesbeiana tadpoles (mean total length $\pm \mathrm{SD}=5.21 \pm 0.60, N=56$ ) were used. Tadpoles of $H$. semilineata that metamorphosed in the laboratory were returned to their original collection site. Samples of tadpoles and adults are deposited in the collection Célio F. B. Haddad (CFBH), Depto Zoologia, Instituto de Biociências, Universidade Estadual Paulista, Rio Claro, São Paulo.

The schooling behavior of $H$. semilineata tadpoles was studied both in the natural environment and under controlled conditions where they were maintained in tanks of $140 \mathrm{~cm}$ x $130 \mathrm{~cm}$ with water at a depth of $50 \mathrm{~cm}$. The form of the school and the position and movement of the individuals in relation to the rest of the tadpoles were recorded.

The swimming behavior of individual tadpoles was recorded by obtaining the two measurements described below. For both measurements, two boxes $(47 \times 33 \mathrm{~cm})$ were used, filled with approximately 10 liters of water $(7 \mathrm{~cm}$ deep), each one containing 40 tadpoles of one of the species. The time interval in which the tadpoles remained stationary was measured with a stopwatch. Every five minutes, one tadpole was chosen haphazardly among those that were swimming and when it ceased moving, the time it took to become active again was registered. This procedure was repeated 30 times for each species. The number of individuals that were swimming simultaneously among the 40 tadpoles of each species every five minutes was also recorded; this was done 30 times for each species. Tadpoles were kept in the boxes for $24 \mathrm{~h}$ before the measurements were initialized. Differences between values were verified using the t-test or Mann-Whitney test (SOKAL \& ROHLF, 1981)

\section{RESULTS}

Schools of $H$. semilineata tadpoles are very common in nature and isolated individuals usually do not remain far from the group for long. Schooling behavior also occurred in the experimental tanks and the tadpoles usually remained aggregated in boxes or aquaria. Tadpole schools, both in nature as well as in the tanks, can be classified as three distinct types according to their format, density, and individual orientation: dense school, loose school, and displacing school.

The dense school was usually in the form of a sphere with a high density of individuals that are not polarized (fig. 1). The tadpoles are in constant movement with their bodies generally directed toward the center of the school and their tails toward the edge, maintaining physical contact. Movement usually began with one of the tadpoles and then spread throughout the school. This spherical mass could be located near the bottom or in the water column and remained stationary or moved very slowly. This behavior varied when the tadpoles were feeding and the dense mass was not spherical but was spread along the food item. Two forms of slow displacement were observed: (a) displacement analogous to a rolling ball, due to the fact that the individuals were always swimming toward the center of the sphere and changing positions continually and (b) displacement produced by an amoeboid movement in the direction of their objective, where the tadpoles 


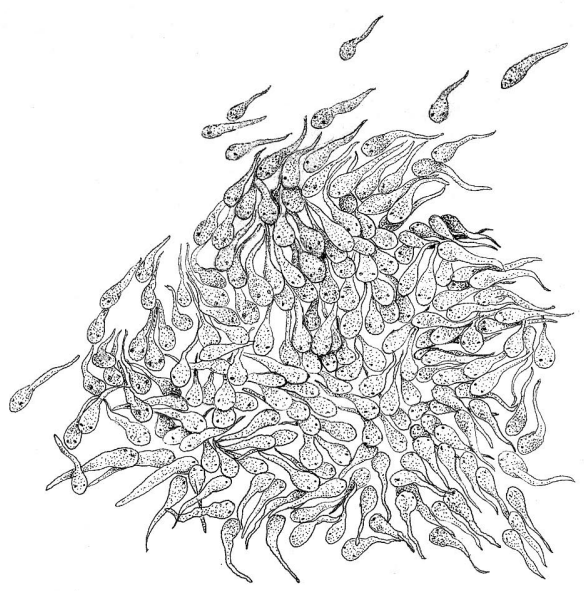

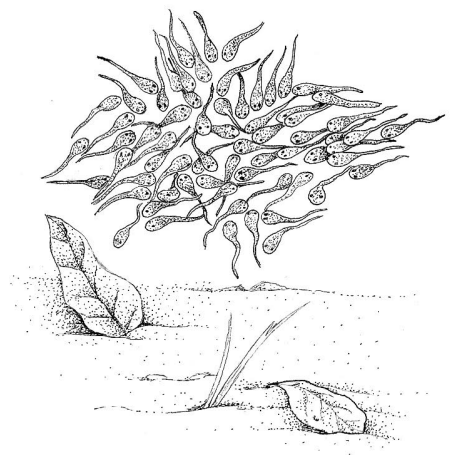

2

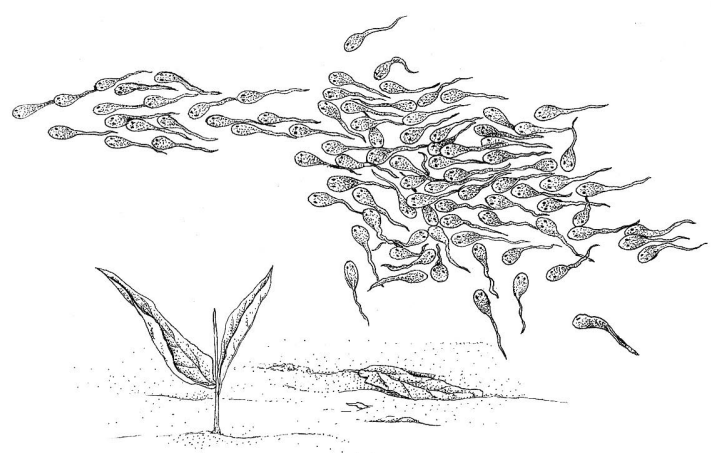

b
C

Figs. 1, 2. Hyla semilineata tadpoles: 1 , a dense school, showing a high density of non-polarized individuals; 2, two loose schools ( $\mathrm{a}$ and $\mathrm{c}$ ) that have been formed by the splitting of a dense school. A displacing school (b) is forming a connection between the two loose schools. Note how, in the displacing school, the tadpoles are moving in a relatively straight line made up of a few rows of polarized individuals oriented in an almost parallel manner. 
in front or behind the school positioned themselves in such a way that the extremities of the school resembled pseudopods.

In the loose school, tadpoles were more dispersed than in the dense school and were not organized (fig. 2a). They remained stationary most of the time, not swimming or feeding in conjunction with other tadpoles. The loose school seemed to be temporary, since it occurred after the tadpoles had dispersed due to disturbance in the water and usualluy formed dense schools again after a variable amount of time.

The displacing school occurred when the dense school became less dense and either split into two or more smaller schools or displaced itself to another location. On these occasions, the tadpoles displaced themselves in a relatively straight line made up of one or more rows of polarized individuals oriented in an almost parallel manner (fig. $2 b$ ). The displacing school sometimes formed a connection between the parts of a dense school that had separated (fig. 2).

The following results were obtained in the measurements used to test the swimming behavior of the tadpoles. The tadpoles of H. semilineata (fig. 3) remained stationary ( $x \pm$ $\mathrm{SD}=3.52 \mathrm{~s} \pm 4.0$, range: $0.52-16.84 \mathrm{~s}, N=30$ individuals) for significantly less time ( $t$ $=4.79, P<0.001)$ than did the bullfrog tadpoles $(21.1 \mathrm{~s} \pm 22.27$, range: $1.55-74.54 \mathrm{~s}, N$ $=30$ individuals). The number of tadpoles of $H$. semilineata that were moving simultaneously (fig. 4), among 40 analyzed individuals $(x \pm \mathrm{SD}=34.9$ individuals \pm 2.8 , range: 27 - 40 individuals, $N=30$ replications) was significantly greater $(\mathrm{t}=5.37, P<$ $0.001)$ than the number of tadpoles of $R$. catesbeiana Shaw, 1802 moving simultaneously (14.8 individuals \pm 4.7 , range: 3 - 23 individuals, $N=30$ replications).
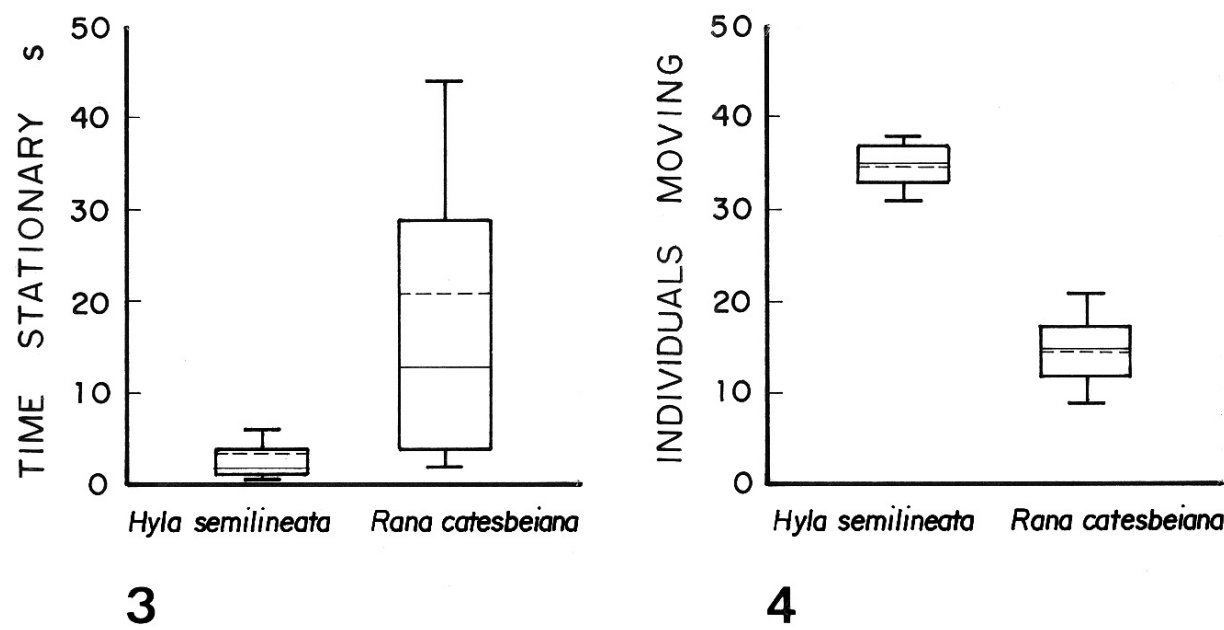

Figs. 3, 4. 3, the time that the tadpoles of Hyla semilineata and Rana catesbeiana remained stationary; 4, number of individuals moving in a sample of 40 individuals. The top of the box indicates the $25^{\text {th }}$ percentile, the continuous line represents the median and the bottom of the box indicates the $75^{\text {th }}$ percentile. The bars above and below the boxes indicate the $90^{\text {th }}$ and $10^{\text {th }}$ percentiles, respectively. The dashed line represents the mean. 


\section{DISCUSSION}

The schools formed by H. semilineata tadpoles partially correspond to Type III schools described by CALDWELL (1989). In the description of the Type III school, CALDWELL (1989) states that the tadpoles are never polarized and this does not apply for H. semilineata tadpoles. The tadpoles of this species may form three different school structures that apparently correspond to the classification of BEISWENGER (1975). The third type of school structure, or displacing school, where the individuals swim in a polarized manner was not observed by CALDWELL (1989) for $H$. geographica tadpoles (a species closely allied to $H$. semilineata, see HEURSEL \& DE SÁ, 1999). Schools of $H$. geographica tadpoles seemed to move only as a spherical ball (CALDWELL, 1989) which could displace itself slowly or rapidly, unlike that observed for $H$. semilineata that moved only slowly. The formation of dense, spherical masses where the tadpoles of $H$. semilineata maintain physical contact can be seen in nature, in tanks, and even in aquaria where space is restricted. DUELLMAN \& LESCURE (1973) suggest that dense aggregations may be maintained by the constant contact between the members. Nevertheless, the number of tadpoles present may be an important factor for the formation and maintenance of the aggregation (WASSERSUG, 1973).

BEISWENGER (1975) suggested that the co-ordinated swimming and budging among the tadpoles of Bufo americanus Holbrook, 1836 keeps them together as do their reactions to light, temperature, and food. According to Duellman \& LeSCuRE (1973), the less physical contact between individuals at the edge of the school could induce the swimming movements to the center of the school or the lateral movement similar to a rolling ball. The schooling behavior of $H$. semilineata tadpoles may be explained by the "selfish herd" theory where the individuals of a population tend to aggregate to reduce the predation risk area, positioning themselves in the empty space among other individuals (HAMILTON, 1971).

Hoff et al. (1999) arranged tadpole swimming behaviour into two categories. The first includes tadpoles that exhibit "rapid bursts to evade predators" and the second includes individuals that exhibit "very slow swimming between patches of food or in midwater aggregates". Even in the latter category, the tadpoles do not swim steadily for very long.

Hyla semilineata tadpoles remained stationary for one sixth of the time that the bullfrog tadpoles did and the number of individuals of $H$. semilineata tadpoles moving at any given moment was about seven times greater. This constant movement of $H$. semilineata tadpoles is possibly related to their schooling behavior, which together would increase the foraging efficiency of the tadpoles by causing a resuspension of bottom sediment and food, as suggested by BEISWENGER (1975) and KATZ et al. (1981). However, this type of swimming behavior could also help to enhance the conspicuousness of the $H$. semilineata tadpoles. Like tadpoles of $H$. semilineata, larvae of Bufo bufo (Linnaeus, 1758) have a swimming behavior that makes them highly conspicuous (CHOVANEC, 1992), while the stationary behavior of $R$. catesbeiana tadpoles rarely offers a visual stimulus to the predator (BRODIE et al., 1974; CAldwell et al., 1980; Feder, 1983; Chovanec, 1992). The tadpoles of $R$. catesbeiana seem to exhibit a behavior similar to that of $R$. dalmatina Bonaparte, 1840 larvae (CHOVANEC, 1992) that can be explained by their cryptic coloration, since they probably remain camouflaged at the bottom of ponds and rivers and escape rapidly when disturbed. The tadpoles of $R$. catesbeiana therefore fall into the first tadpole-swimming category suggested by Hoff et al. (1999). The tadpoles of Bufo bufo and H. geographica are vulnerable to 
odonate larvae that are oblivious to their unpalatability, but are attracted by their constant movement (CAldwell, 1989; Azevedo-Ramos et al., 1992; Chovanec, 1992). This same movement may also attract vertebrate predators that react to the unpalatability and learn to avoid the tadpoles of $H$. semilineata (HeURSEL \& HADDAD, 1999). These predators may relate the bad taste of the larvae to their constant movement as well as to their dark coloration. The fact that tadpoles of $H$. semilineata keep swimming most of the time, as opposed to the general rule where steady swimming in tadpoles does not exist (Hoff et al., 1999), may increase the effect of their aposematism.

Acknowledgments. To the Centro de Aqüicultura, Universidade Estadual Paulista and the Instituto de Pesca, Pindamonhangaba for providing the Rana catesbeiana tadpoles. Jaime Somera expertly drew the diagrams. The research was supported by FAPESP (undergraduate grant to A. d'Heursel, process 94/0388-6 and grant to C. F. B. Haddad, process 95/9269-2) and CNPq (fellowship to C.F.B. Haddad).

\section{REFERENCES}

Azevedo-Ramos, C.; Van Sluys, M. et al. 1992. Influence of tadpole movement on predation by odonate naiads. J. Herpetol., Athens, 26:335-338.

Beiswenger, R. E. 1975. Structure and function in aggregations of tadpoles of the american toad, Bufo americanus. Herpetologica, Chicago, 31:222-233.

Brodie, E. D., JR.; Johnson, J. A. \& DodD, K. C. 1974. Immobility as a defensive behavior in salamander. Herpetologica, Chicago, 30:79-85.

Caldwell, J. P. 1989. Structure and behavior of Hyla geographica tadpole schools, with comments on classification of group behavior in tadpoles. Copeia, Lawrence, 1989:938-950.

Caldwell, J. P.; Thorp, J. H. \& Jervey, T. O. 1980. Predator-prey relationships among larval dragonflies, salamanders, and frogs. Oecologia, Berlin, 46:285-289.

Chovanec, A. 1992. The influence of tadpole swimming behaviour on predation by dragonfly nymphs. Amphibia-Reptilia, Leiden, 13:341-349.

Duellman, W. E. \& Lescure, J. 1973. Life history and ecology of the hylid frog Osteocephalus taurinus with observations on larval behavior. Occas. Pap. Mus. Nat. Hist. Univ. Kansas, Lawrence, 13:1-12.

Eterovick, P. C. \& Sazima, I. 1999. Description of the tadpole of Bufo rufus with notes on aggregative behaviour. J. Herpetol., St. Louis, 33:711-713.

FEDER, M. E. 1983. The relation of air breathing and locomotion to predation on tadpoles, Rana berlandieri by turtles. Physiol. Zool., Chicago, 56:522-531.

GosNER, K. L. 1960. A simplified table for staging anuran embryos and larvae with notes on identification. Herpetologica, Chicago, 16:183-190.

Guilford, T. 1988. The evolution of conspicuous coloration. Am. Nat., Chicago, 131:7-21.

Hamilton, W. D. 1971. Geometry for the selfish herd. J. Theor. Biol., London, 31:295-311.

Heursel, A. D' \& DE SÁ, R. 1999. Comparing the tadpoles of Hyla geographica and Hyla semilineata. J. Herpetol., St. Louis, 33:353-361.

Heursel, A. D' \& HadDad, C. F. B. 1999. Unpalatability of Hyla semilineata tadpoles (Anura) to captive and free-ranging vertebrate predators. Ethol. Ecol. Evol., Firenze, 11:339-348.

Hoff, K. S.; Blaustein, A. R. et al. 1999. Behaviour: Interactions and their consequences. In: McDiarmid, R.W. \& Altig, R. ed. Tadpoles: The biology of anuran larvae. Chicago, University of Chicago. p.215-239.

Katz, L. C.; Potel, M. J. \& Wassersug, R. J. 1981. Structure and mechanisms of schooling in tadpoles of the clawed frog, Xenopus laevis. Anim. Behav., London, 29:20-33.

SoKal, R. R. \& Rohlf, F. J. 1981. Biometry. San Francisco, W. H. Freeman. 776p.

WaLDMAn, B. 1982. Sibling association among schooling toad tadpoles: Field evidence and implications. Anim. Behav., London, 30:700-713.

WASSERSUG, R. 1973. Aspects of social behaviour in anuran larvae. In: VIAL, J. L. ed. Evolutionary biology of the anurans. Columbia, University of Missouri. p. 273-297.

Recebido em 05.02.2001; aceito em 15.02.2002. 